\title{
Phthalate exposure and health outcomes
}

\begin{abstract}
Phthalates are used in commercial products as softners of plastics, solvents in perfumes and additives to hair sprays, lubricants and insect repellents. The wide spread use of phthalate results in multiple human exposure routes i.e., ingestion, inhalation and dermal exposure. In the present review, a detailed account of respiratory toxicity, reproductive toxicity, developmental toxicity, endocrine disruptors and genotoxicity of human exposure to phthalate is mentioned in detail.
\end{abstract}

Key words: Exposure, human, phthalate

\section{INTRODUCTION}

Phthalates represent a large class of chemicals that are widely used in commercial products. Phthalates are dialkyl or alkyl /aryl esters of 1,2-benzene dicarboxylic acids which have numerous uses as softeners of plastics, solvents in perfumes and additives to hair sprays, lubricants and insect repellents. ${ }^{[1-5]}$ In the residential construction or automotive industries diethyl hexyl phthalate, dibutyl phthalate and butyl benzyl phthalate are used in floorings, paints, adhesives, wood finishes, wall paper and in PVC products. The high levels of mono ethyl phthalates across the population are most likely associated with the every day use of consumer products that commonly contain diethyl phthalates (DEP), such as detergents, soaps, cosmetics, shampoo and perfumes. Phthaltes are multifunctional chemicals used to hold colour and scent in consumer and personal care products. Phthalates are also present in drinking water, air and food. Diethyl hexyl phthalate (DEHP), one of the more commonly used phthalates leaches from blood products, intravenous and dialysate bags and tubings made with PVC.

In particular di - (2-ethylhexyl) phthalate (DEHP) is the most commonly used plasticizer. Globally, more than 18 billion pounds of phthalates are used each year and well above 2 million tons of DEHP alone are produced annually worldwide. ${ }^{[6]}$ Other important phthaltes production and application wise are DEP, dibutyl phthalate (DBP), di-iso- and di-n-butylphthalate (DiBuP, DnBuP), butyl-benzylphthalate (BBzP), di-isononylphthalte (DiNP) or di-n-octylphthalte (DnOP) ${ }^{[7]}$ The potential for non occupational exposure to phthaltes is high given their use in a vast range of consumable products and because they are not covalently bound to the other chemicals in the formulations. After exposure, phthalates are rapidly hydrolyzed to their respective monoesters which can be further biotransformed to oxidative metabolites.

The wide spread use of phthalates results in multiple human exposure routes. Humans are exposed to these compounds through ingestion, inhalation and dermal exposure for their whole lifetime, since the intrauterine life. ${ }^{[8-10]}$ Dermal and inhalative exposures are considered to be the major route of exposure to DEP that is found in hygiene products such as soap, shampoo and conditioners. DEP and DBP are used extensively in products with volatile components such as perfumes, nail polishes and hair sprays possibly leading to inhalation and efficient absorption through the lungs. Dermal absorption also occurs at a significant rate for phthalates with short side chains such as DEP, DBP and BzBP.[11] In contrast, for phthalates that are used mainly as plasticizers, such as DEHP, oral exposures predominate. ${ }^{[12]}$

\section{METABOLISIM OF PHTHALATES}

Phthalates are lipophilic compounds that appear not to bioaccumulate. ${ }^{[13]}$ These are rapidly metabolized to their respective monoesters and further oxidative products which are glucuronidated and excreted through the urine and feces. ${ }^{[14-16]}$ Recent metabolic studies have shown that long alkyl chain phthaltes such as dioctryl phthalate are broken down to small chain phthalates before
S. K. Rastogi, C. Kesavachandran*, Farzana Mahdi, Amit Pandey Era's Lucknow Medical College and Hospital, Lucknow, *Epidemiology Section, Industrial Toxicology Research Centre (CSIR), Lucknow, India

For correspondence: Dr. S. K. Rastogi, Department of Physiology, Era's Lucknow Medical College and Hospital, Lucknow, India.

E-mail:

subhodhrastogi@yahoo.com

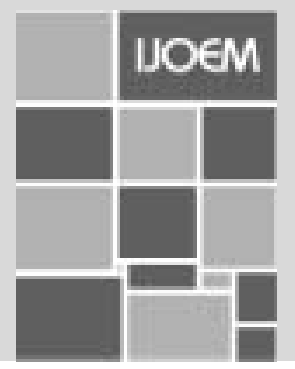


elimination from the body.

\section{URINARY MEASURES OF PHTHALATES}

Until recently, there was no direct way to measure phthalate exposure in environmentally and occupationally exposed individuals. We also had no population data on urinary phthalates levels and to date there are no published data that indicate sources of exposure associated with phthalates. With the recent studies on phthalates several urinary biomarkers are now available to assess specific phthalate monoesters. ${ }^{[17]}$ These biomarkers reflect recent exposure and have been demonstrated to be reliable. ${ }^{[18]}$ The measurement of monoester metabolites have been preferred over the metabolites of diester phthalates because the former have the added advantage of having longer biologic half life (12 $\mathrm{hrs}$ ) than the latter ones ( $<3 \mathrm{hrs})$. Furthermore, most of the human toxicity is associated with the phthalate monoesters. The recent literature has shown that seven urinary monoester metabolites are now measured in spot urine samples using high pressure liquid chromatography mass spectrometry. ${ }^{[19]}$ Mono benzyl phthalate (MBZP), mono-butyl phthalate (MBP), monocyclohexyl phthalate (MCHP), monoethyl phthalate (MEP), mono-ethyl hexyl phthalate (MEHP), mono-isononyl phthalate (MINP), mono-octryl phthalate (MOP) etc. have been recommended as urinary biomarkers of phthalate exposure. ${ }^{[19]}$ The National Health and Nutrition examination surveys ${ }^{[2]}$ which analyzed several hundreds of urine samples indicated that not all metabolites are available in the morning void samples. The four phthalates MBP, MBZP, MEP and MEHP have been detected in most of the urine samples (97 to 99\% of the sample analyzed) thereby showing the reliability and sensitivity of these monoester metabolites. However, while conducting such type of estimation it is of utmost importance to have a detailed personal history of the individual undergoing the analysis as sex and cigarette smoking are the confounding factors influencing the urinary metabolites of phthalates. Women have been reported to have higher urinary levels than men. ${ }^{[21]}$ The fact that women had higher concentration of urinary metabolites than men was most likely attributable to women's increased use of personal care products, such as beauty and hair care products, cosmetics and perfumes. It is not known whether the observed differences in males and females represent different underlying biology or different patterns of exposure. The higher levels of urinary biomarkers in women may be due to their greater exposure via the dermal route whereas men may have greater exposure via inhalation. Similarly adults and adolescents have higher levels than in children are consistent with the known behavioral uses of phthalate containing consumer products. Other factors viz, socio economic status and smoking habit have been shown to influence the level of urinary metabolites of monoester phthalates. The socio economic status appear to have a weak association with phthalate levels. ${ }^{[22]}$

\section{HEALTH OUTCOMES}

Human studies are scare, but suggestive, as frequently reporting an association between phthalate exposure and health risks. The presence of phthalate metabolites in human body fluids does not by itself mean that phthalates cause disease. The adverse health effects of phthalate exposure on human population are most likely associated with the everyday use of consumer products that commonly contain a variety of phthalates like DEP, MEP, MBP etc. The recent studies suggest a broad spectrum of health outcomes associated with phthalate exposure.

\section{RESPIRATORY EFFECTS}

Potential phthalate exposure has been associated with respiratory symptoms and disease in young children exposed to building materials, synthetic bedding. ${ }^{[23-24]}$ Earlier study ${ }^{[26]}$ observed an increased incidence of lower respiratory symptoms and bronchial obstruction among children in homes with plastic wall materials and PVC building materials. Similar findings have also been reported earlier ${ }^{[25]}$ on Australian infants using synthetic bedding materials. The children had higher odds of wheeze at 7 years of age than did other children. Earlier report ${ }^{[26-27,63]}$ show higher rates of respiratory symptoms among beauticians (hair dressers). These respiratory effects could be due to phthalate exposure through inhalation via respiratory routes (air-borne suspended particulates). Earlier report ${ }^{[27]}$ mentioned that hair dressers had greater reduction in respiratory parameters. The respiratory impact of phthalates in adults was reported earlier. ${ }^{[2]}$ They assessed the association between phthalate exposure and four pulmonary function parameters (FVC, FEV1, PEF and MMEF) and found that MBP was significantly associated with decrements in FVC, FEV1, PEF and MMEF thereby contributing to respiratory impairment. However, MEHP was not adversely associated with any of the pulmonary function parameters evaluated.

\section{REPRODUCTIVE TOXICITY}

Evidence of population exposed to phthalates as well as in vitro studies suggest that some phthalates are normally active. The animal studies showed association between some phthalates and testicular toxicity. The National Institute of Occupational Safety and Health has classified DBP as a high priority chemical for study because of its widespread use and its reproductive toxicity. It is toxic to the testes, possibly through its metabolite, MBP. ${ }^{[29]}$ Of the phthalate most commonly used, DEHP and DBP and their metabolites have the greatest potential for toxicity. DEHP has been reported to suppress the estradiol and ovulation in cycling rats. It is a 
reproductive toxicant and is carcinogenic in animal models. The phthalates have been also shown to cause endocrine disruption causing testicular toxicity, decreased fertility, decreased sperm motility and decreased milk synthesis. Several phthalates viz, DEHP, DBP and BZP are teratogenic in animals. ${ }^{[30,31]}$ Animal toxicology of several phthalates have been studied. DEHP is a rodent liver carcinogen through a mechanism thought to involve peroxisome proliferation. ${ }^{[32]}$ However, carcinogenicity by this mechanism is unlikely to be relevant to humans. ${ }^{[33]}$

Several phthalates and their metabolic products have been shown to be developmental and reproductive toxicants affecting particularly male reproductive development ${ }^{[34-37]}$ and are suspected of having endocrine disrupting or modulating effects. ${ }^{[38]}$ An endocrine disruptor is a chemical with the potential to alter hormone action within the body. ${ }^{[39]}$ Thus these chemicals have been found to interfere with the function of endocrine system which is responsible for growth, sexual development and many other essential physiological functions both in males and females. ${ }^{[40-41]}$

Gestational and lactational exposures to large doses of DBP and its metabolite MBP in rats cause male reproductive tract malformation. ${ }^{[36]}$ DBP reduces the production of testosterone by fetal testis through an antiandrogenic mechanism. ${ }^{[42]}$ The active testicular toxicant may be DEHP metabolite MEHP. ${ }^{[43-44]}$

\section{DEVELOPIMENTAL TOXICITY}

Results from animal toxicology studies have demonstrated endocrine modulating effects from phthalate exposure ${ }^{[31]}$ For example DEHP alters thyroid structure and activity in male wistar rats and produces reproductive and developmental toxicities in rodents. ${ }^{[45]}$ In male rodents, the testes are a primary target tissue and exposure to high doses of DEHP results in decreased testicular weights and tubular atrophy. ${ }^{[4]}$ DEHP is a known reproductive and developmental toxicant in animals exerting its toxicity already in utero. Some effects are malformed reproductive organs, a decreased anogenital distance, retained nipples at birth, a general decrease in mating, pregnancy or fertility, reduced prenatal and post natal survival of the offspring, reduced sperm counts or reduced reproductive organ weights. ${ }^{[4]}$ DEHP is known to produce decreased testicular weight, ${ }^{[46]}$ severe testicular atrophy and reduced weight of sex organs in adult male rats by a mechanism thought to involve decreased fetal testosterone synthesis during male sexual differentiation. ${ }^{[35]}$

Some phthalates and their metabolites act functionally as antiandrogens during the pre natal period ${ }^{[35,47,48]}$ and cause reproductive and developmental toxicity in animals especially in males. Some developmental effects include reduction in androgen dependent tissues (Seminal vesicles, epididymis, prostate. ${ }^{[38,49,50]}$

\section{ENDOCRINE DISRUPTORS}

DEHP is also a suspected human endocrine disruptor/ modulator. ${ }^{[3,40,51-54]}$ Some phthalates are hormonally active $\mathrm{e}^{[55,56]}$ and animal studies showed associations between some phthalates and testicular toxicity ${ }^{[35,57-59]}$ has generated both public and scientific concern about potential reproductive effects of phthalates.

\section{GENOTOXICITY}

Recent in vitro studies using the alkaline comet assay (single cell gel electrophoresis) found di-n-butyl phthalate (DBP) and di-isobutyl phthalate (DiBP) to be genotoxic in human epithelial cells of the upper aerodigestive tract ${ }^{[60]}$ as well as in mucosal cells and lymphocytes. ${ }^{[61]}$ Additionally, the comet assay was used to detect DNA damage in human lymphocytes induced by in vitro exposure to DEHP and MEHP. ${ }^{[62]}$ Using the alkaline comet assay, researchers have found evidence of genotoxicity with in vitro studies examining lymphocytes and mucosal cells of digestive tract after exposure to DBP and DiBP.

In another study using the alkaline comet assay on human leucocytes, an association between MEHP and DEHP and increased tail movements was found..$^{[60-62]}$

\section{REFERENCES}

1. ATSDR. Toxicological profile for diethylphthalate. U.S. Department of Health and Human Services, Public Health Service, Agency for Toxic Substances and Disease Registry: Atlanta, GA; 1995.

2. ATSDR. Toxicological profile for di-n-octylphthalate. U.S. Department of Health and Human Services, Public Health Service, Agency for Toxic Substances and Disease Registry: Atlanta, GA; 1997.

3. ATSDR. Toxicological profile for di-n-butyl phthalate. U.S. Department of Health and Human Services, Public Health Service, Agency for Toxic Substances and Disease Registry: Atlanta, GA; 2001.

4. ATSDR. Toxicological profile for di(2-ethylhexyl)phthalate (DEHP). U.S. Department of Health and Human Services, Public Health Service, Agency for Toxic Substances and Disease Registry: Atlanta, GA; 2002.

5. David RM, McKee RH, Butala JH. Esters of aromatic mono-di and tricarboxylic acids, aromatic diacids and di-tri or polyalcohols. In: Patly's Toxicology. John Wiley and Sons: New York; 2001. p. 635932.

6. Lorz PM, Towae FK, Enke W, Jäckh R, Bhargava N. Phthalic acid and derivatives. Ullmann's encyclopedia of industrial chemistry. WileyVCH: Weinheim; 2002.

7. Koch HM, Rossbach B, Drexler H, Angerer J. Internal exposure of the general population to DEHP and other phthalates determination of secondary and primary phthalate monoester metabolites in urine. Environ Res 2003;93:177-85.

8. Adibi JJ, Perera FP, Jedrychowski W, Camann DE, Barr D, Jacek R, et al. Prenatal exposures to phthalates among women in New York City 
and Krakow, Poland. Environ Health Perspect 2003;111:1719-22.

9. Latini G, De Felice C, Presta G, Del Vecchio A, Paris I, Ruggieri F, et al. Exposure to Di-(2-Ethylhexyl)-Phthalate in humans during pregnancy: A preliminary report. Biol Neonate 2003;83:22-4.

10. Latini G, De Felice C, Presta G, Del Vecchio A, Paris I, Ruggieri F, et al. In utero exposure to Di-(2-Ethylhexyl)-phthalate and duration of human pregnancy. Environ Health Perspect 2003;111:1783-5.

11. Elsisi AE, Carter DE, Sipes IG. Dermal absorption of phthalate diesters in rats. Fundam Appl Toxicol 1989;12:70-7.

12. Doull J, Cattley R, Elcombe C, Lake BG, Swenberg J, Wilkinson C, et al. A cancer risk assessment of di(2-ethylhexyl)phthalate: Application of the new U.S. EPA Risk Assessment Guidelines. Regul Toxicol Pharmacol 1999;29:327-57.

13. Schmid P, Schlatter C. Excretion and metabolism of di(2-ethylhexyl) phthalate in man. Xenobiotica 1985;15:251-6.

14. Albro PW, Thomas R, Fishbein L. Metabolism of Di-ethylhexhyl phthalate by rats: Isolation and characterization of the urinary metabolites. J Chromatogr 1973;76:321-30.

15. Ward JM, Diwan BA, Ohshima M, Hu H, Schuller HM, Rice JM. Tumor initiating and promoting activities of di (2-ethylhexyl) phthalate in vivo and in vitro. Environ Health Perspect 1986;65:279-91.

16. Dirven HA, van den Broek PH, Jongeneelen FJ. Determination of four metabolites of the plasticizer di(2-ethylhexyl)phthalate in human urine samples. Int Arch Occup Environ Health 1993;64:555-60.

17. Blount BC, Milgram KE, Silva MJ, Malek NA, Reidy JA, Needham LL, et al. Quantitative detection of eight phthalate metabolites in human urine using HPLC-APCI-MS/MS. Anal Chem 2000;72:4127-34.

18. Hoppin JA, Brock JW, Davis BJ, Baird DD. Reproducibility of urinary phthalate metabolites in first morning urine samples. Environ Health Perspect 2002;110:515-8.

19. Blount BC, Silva MJ, Caudill SP, Needham LL, Pirkle JL, Sampson EJ, et al. Levels of seven urinary phthalate metabolites in a human reference population. Environ Health Perspect 2000;108:979-82.

20. NCHS. $3^{\text {rd }}$ National Health and Nutrition examination survey, 198894. NHANES III Raw Spirometry. National Center for Health Statistics, Hyattsville, MD Data File. Series 11, 9a: 2001.

21. CDC. National Report on Human Exposure to Environmental Chemicals. Centers for Disease Control and Prevention. National Center for Environmental Health: Atlanta, GA; 2003.

22. Koo JW, Parham F, Kohn MC, Masten SA, Brock JW, Needham LL, et al. The association between biomarker based exposure estimates for phthaltes and demographic factors in a human reference population. Environ Health Perspect 2002;110:405-10.

23. Jaakkola JJ, Oie L, Nafstad P, Botten G, Samuelsen SO, Magnus P. Interior surface materials in the home and the development of bronchial obstruction in young children in Oslo, Norway. Am J Public Health 1999;89:188-92.

24. Jaakkola JJ, Verkasalo PK, Jaakkola N. Plastic wall materials in the home and respiratory health in young children. Am J Public Health 2000;90:797-9.

25. Ponsonby AL, Dwyer T, Kemp A, Cochrane J, Couper D, Carmichael A. Synthetic bedding and wheeze in childhood. Epidemiology 2003; 14:37-44.

26. Hollund BE, Moen BE, Lygre SH, Florvaag E, Omenaas E. Prevalence of airway symptoms among hairdressers in Bergen, Norway. Occup Environ Med 2001;58:780-5.

27. Iwatsubo Y, Matrat M, Brochard P, Ameille J, Choudat D, Conso F, et al. Healthy worker effect and changes in respiratory symptoms and lung function in hairdressing apprentices. Occup Environ Med 2003;60:831-40.

28. Hoppin JA, Ulmer R, London SJ. Phthalate exposure and pulmonary function. Environ Health Perspect 2004;112:571-4.

29. Heindel JJ, Powell CJ. Phthalate ester effects on rat sertolli cell function in vitro: Effects of phthalate side chain and age of animal. Toxicol
Appl Pharmacol 1992;115:116-23.

30. Ema M, Harazono A, Miyawaki E, Ogawa Y. Developmental toxicity of mono-n-benzyl phthalate, one of the major metabolites of the plasticizer n-butyl benzyl phthalate, in rats. Toxicol Lett 1996;86:1925.

31. Gray LE Jr, Wolf C, Lambright C, Mann P, Price M, Cooper RL, et al. Administration of potentially antiandrogenic pesticides (procymidone, linuron, iprodione, chlozolinate, p,p'-DDE, and ketoconazole) and toxic substances (dibutyl- and diethylhexyl phthalate, PCB 169, and ethane dimethane sulphonate) during sexual differentiation produces diverse profiles of reproductive malformations in the male rat. Toxicol Ind Health 1999;15:94-118.

32. David RM, Moore MR, Cifone MA, Finney DC, Guest D. Chronic peroxisome proliferation and hepatomegaly associated with hepatocellular tumorigenesis of di 2-ethylhexylphthalte and the effects of recovery. Toxicol Sci 1999;50:195-205.

33. Ema M, Amano H, Itami T, Kawasaki H. Teratogenic evaluation of din-butyl phthalate in rats. Toxicol Lett 1993;69:197-203.

34. Gray LE Jr, Ostby J, Furr J, Price M, Veeramachaneni DN, Parks L. Perinatal exposure to the phthalates DEHP, BBP and DINP, but not DEP, DMP or DOTP, alters sexual differentiation of the male rat. Toxicol Sci 2000;58:350-65.

35. Parks LG, Ostby JS, Lambright CR, Abbott BD, Klinefelter GR, Barlow $\mathrm{NJ}$, et al. The plasticizer diethylhexyl phthate induces malformations by decreasing fetal testosterone synthesis during sexual differentiation in the male rat. Toxicol Sci 2000;58:339-49.

36. Ema M, Miyawaki E. Adverse effects on development of the reproductive system in male offspring of rats given monobutyl phthalate, a metabolite of dibutyl phthalate, during late pregnancy. Reprod Toxicol 2001;15:189-94.

37. Wilson VS, Lambright C, Furr J, Ostby J, Wood C, Held G, et al. Phthalate ester-induced gubernacular lesions are associated with reduced ins13 gene expression in the fetal rat testis. Toxicol Lett 2004;146:207-15.

38. Latini G, Verrotti A, De Felice C. DI-2-ethylhexyl phthalate and endocrine disruption: A review. Curr Drug Targets Immune Endocr Metabol Disord 2004;4:37-40.

39. Sharpe RM, Irvine DS. How strong is the evidence of a link between environmental chemicals and adverse effects on human reproductive health? BMJ 2004;328:447-51.

40. Lovekamp-Swan T, Davis BJ. Mechanisms of phthalate ester toxicity in the female reproductive system. Environ Health Perspect 2003;111:139-45.

41. Sharpe RM. Hormones and testis development and the possible adverse effects of environmental chemicals. Toxicol Lett 2001;120:221-32.

42. Mylchreest E, Sar M, Wallace DG, Foster PM. Fetal testosterone insufficiency and abnormal proliferation of leydig cells and gonocytes in rats exposed to di n-butyl phthalate. Reprod Toxicol 2002;16:1928.

43. Gray TJ, Beamand JA. Effect of some phthalate esters and other testicular toxins on primary cultures of testicular cells. Food Chem Toxicol 1984;22:123-31.

44. Gray TJ, Gangolli SD. Aspects of the testicular toxicity of phthalate esters. Environ Health Perspect 1986;65:229-35.

45. Kavlock R, Boeckelheide K, Chapin R, Cunningham M, Faustman E, Foster P, et al. NTP Centre for evaluation of risks to human reproduction: Phthalates expert panel report on the reproductive and developmental toxicity of di (2-ethylhexyl) phthalate. Reprod Toxicol 2002;16:529-653.

46. Sjoberg P, Lindqvist NG, Ploen L. Age dependent response of rat testes to di (2-ethylhexyl) phthalate. Environ Health Perspect 1986;65:23742.

47. Moore RW, Rudy TA, Lin TM, Ko K, Peterson RE. Abnormalities of sexual development in male rats with in utero and lactational exposure 
to the antiandrogenic plasticizer di (2-ethylhexyl) phthalate. Environ Hlth Perspect 2001;109:229-37.

48. Mylchreest E, Cattley RC, Foster PM. Male reproductive tract malformations in rats following gestational and lactational exposure to di(n-butyl) phthalate. Reprod Toxicol 1988;43:47-60.

49. Agarwal DK, Eustsi S, Lamb JC, Reel JR, Kluwe WM. Effects of di(2ethylhexyl) phthalate on the gonadal pathophysiology, sperm morphology and reproductive performance of male rats. Environ Health Perspect 1986;65:343-50.

50. Foster PM, Mylchreest E, Gaido KW, Sar M. Effects of phthalate esters on the developing reproductive tract of male rats. Hum Reprod Update 2001;7:231-5.

51. Akingbemi BT, Ge R, Klinefelter GR, Zirkin BR, Hardy MP. Phthalateinduced Leydig cell hyperplasia is associated with multiple endocrine disturbances. Proc Natl Acad Sci USA 2004;101:775-80.

52. Fisher JS. Environmental anti-androgens and male reproductive health: Focus on phthaltes and testicular dysgenesis syndrome. Reproduction 2004;127:305-15.

53. Sharpe RM. Phthalate exposure during pregnancy and lower anogenital index in boys: Wider implications for the general population? Environ Health Perspect 2005;113:A504-5.

54. Swan SH, Main KM, Liu F, Stewart SL, Kruse RL, Calafat AM, et al. Decrease in anogential distance among male infants with prenatal phthalate exposure. Environ Health Persp 2005;113:1056-61.

55. Harris CA, Henttu P, Parker MG, Sumpter JP. The estrogenic activity of phthalate esters in vitro. Environ Health Perspect 1997;105:802-11.

56. Nakai M, Tabira Y, Asai D, Yakabe Y, Shimyozu T, Noguchi M, et al. Binding characteristics of dialkyl phthalates for the estrogen receptor.
Biochem Biophys Res Commun 1999;254:311-4.

57. Gangolli SD. Testicular effects of phthalate esters. Environ Health Perspect 1982;45:77-84.

58. Li LH, Jester WF, Orth JM. Effects of relatively low levels of mono (2-ethylhexyl) phthalate on cocultured serotolli cells and gonocytes from neonatal rats. Toxicol Appl Pharmacol 1998;153:258-65.

59. Sharpe RM, Fisher JS, Milar MM, Jobling S, Sumpter JP. Gestational and lactational exposure of rats to xenoestrogens results in reduced testicular size and sperm production. Environ Health Perspect 1995;103:1136-43.

60. Kleinsasser NH, Kastenbauer ER, Weissacher H, Muenzenrieder RK, Harreus UA. Phthalates demonstrate genotoxicity on human mucosa of the upper aerodigestive tract. Environ Mol Mutagen 2000;35:9-12.

61. Kleinsasser NH, Weissacher H, Kastenbauer ER, Dirschedi P, Wallner BC, Harreus UA. Altered genotoxicity in mucosal cells of head and neck cancer patients due to environmental pollutants. Eur Arch Otorhinolaryngol 2000;257:337-42.

62. Anderson D, Yu TW, Hinccal F. Effect of some phthalate esters in human cells in the comet assay. Teratog Carcinog Mutagen 1999;19:275-80.

63. Kesavachandran C, Rastogi SK, Mathur N, Bihari V, Singh A. A study of the prevalence of respiratory morbidity and ventilatory obstruction in beauty parlour workers. Ind J Occup Envt Med 2006;10:28-31.

Source of Support: Nil, Conflict of Interest: None declared.

Announcement

\title{
INDIAN ASSOCIATION OF OCCUPATIONAL HEALTH
}

\author{
$1^{\text {st }}-4^{\text {th }}$ February 2007
}

Hosted by Tamilnadu Branch

Venue: Hotel Taj Coromandel, Chennai.

Address for communication :

Marudeshwara Enterprises, A/2, Shanthi Apartments, $18 \mathrm{ttk}$, $1^{\text {st }}$ Cross street, Alwarpet, Chennai - 600 018, phone: 91-44 - 2435 3079, 2432 8152, Tel./Fax : 91-44-2432 0605,

E-mail : marudeshwara_tours@vsnl.com, www.marudeshwara.com

\section{Rush your registrations}

